\title{
Development of transport systems as one of the areas of Industry 4.0
}

\author{
Konstantin Komarov ${ }^{1, *}$ \\ ${ }^{1}$ Siberian Transport University, 630049 Novosibirsk, Russia
}

\begin{abstract}
This article considers the results of research conducted to define the impact of information technology (IT) on the development of regional transport systems (TS) within the subjects of the Russian Federation. The purpose of this paper is to investigate the impact of digitalization on transport systems and to assess its economic consequences. Methods of analytical modelling, ranging and spatial differentiation are used. The differentiated recommendations are offered for cities, agglomerations and regions for assessing the economic consequences of transport digitalization.
\end{abstract}

\section{Introduction}

Active introduction of IT is one of the key methods to improve the efficiency of transport systems. These technologies are well-known from monographs, articles and web sources published in various countries and successfully used in practice [1-4]. However, the introduction of IT in various types of TSs is uneven for a number of reasons, including, but not limited to the specificity of the three levels of the TS:

- $\quad$ Local TSs providing basic production activities in the territory;

- $\quad$ regional TSs, providing inter-district exchange of goods [5];

- $\quad$ state (country) TSs [6-7].

Each of these TSs requires the development of appropriate development models that minimize the transport component in the price of the final product. The resulted expenses connected with work of TSs of all levels reach 39\%, and full transport costs make up $10 \%$ of gross domestic product [1] in economy of Russia. Formation and expansion of unified TS in the Russian Federation takes place on the basis of an evolving system of territorial and local levels. And each of these levels has its own development prospects.

If we talk about the stages of the development of the country's economy in the context of the development of TS ensuring the development of each stage, one can identify three stages here: (1) separation of the transport systems of the former USSR, in which Russia received $59 \%$ of the railways, $49 \%$ of the motor roads and $74 \%$ of the trunk pipelines of the unified transport system of the USSR; (2) the privatization of individual elements of the TS, during which, in particular, more than 100 airlines emerged. In parallel with the process of privatization, a legal framework was established that defines the activity of the transport complex in the market conditions. During this stage (2000-2012), the total passenger

\footnotetext{
*Corresponding author: komarovk12015@gmail.com
} 
turnover for all modes of transport decreased by 23 billion passenger $/ \mathrm{km}$. At the same time, it should be noted that the share of traffic in international communications has significantly increased [1]. The current moment can be attributed to (3) the third stage of development of the TS, which began in 2010. The current stage in the development of transport systems requires the development and implementation of a new model of the TS, which should take into account:

- sectoral and territorial structure of production;

- social and demographic situation in the region;

- place of the district in the national division of labour.

At this stage of the TS development it is important to represent the place and role of transport in the process of implementation of the concept of Industry 4.0.

The purpose of this article is to study the state of affairs in the use of information technologies, which are quite successfully used in a number of industries, but which are used in transport systems in a limited way.

The novelty of the study is the application of analytical modelling for regional TSs.

\section{Materials and methods}

Methods of analytical modelling, ranging and spatial differentiation are used. In this case, analytical modelling involves a qualitative method that allows finding some properties of the solution that optimize the development of the TS. In the absence of functional ratios of the investigated parameters of the transport process, it is advisable to use expert analysis, which allows us to give ordinal estimates of process parameters that can not be directly measured. In this case, the conclusions about the degree of influence of individual parameters of the transport process will be based on the judgments of specialists. The validity and urgency of this methods were widely discussed, in particular, at the conferences "Digital economy and Industry 4.0: Problems and Prospects" INDUSTRY2017 and "Innovative Clusters in the Digital Economy: Theory and Practice" INPROM2017 in St. Petersburg.

\subsection{The concept of Industry 4.0}

In recent years (1990-2016), structural changes occurred in the economic systems of countries all over the world. It has been decided to distinguish three main sectors of the economic system from the point of view of creating added value: industry, agriculture and services, which include transport.

The concept of Industry 4.0 gradually spreads to the whole world. The United States, Japan, China and other developed countries followed the example of Germany. In 2014, a commercial industrial Internet consortium was created in the United States, which included such leaders of the global industry as GE, AT \& T, IMB, Intel and others. Japanese companies, along with German ones, are currently leaders in the digitalization of the economy. They have developed digital interoperability that supports end-to-end processes with business partners through a horizontal value chain. This approach can be fully used in transport in the chain: production-storage-loading-transportation-unloading-warehousing. The coordination of actions in this chain will contribute to a significant increase in operational efficiency through reduction of costs, increase in productivity and improvement of the quality of transport work.

Currently, the concept of Industry 4.0 has acquired the meaning of the fourth industrial revolution, which consists of connecting the real world with the virtual one. At the same time, some new complexes appear that carry the meaning of cyberphysical devices that 
unite the objects of the material world with the virtual world. As a result, some cyberphysical objects emerge that naturally combine into a certain digital ecosystem. The elements of such an ecosystem are robotic production, including "smart stations" as elements of the transformed transport. The concept of Industry 4.0 assumes automation of almost all stages and processes of industrial production, including the transport one. Another feature of the new industrial revolution is that the manufacturer of "smart stations" and all its elements controls the conditions of their operation. It can remotely change settings, including the software in control systems. It also can warn the user in advance about possible disturbances in the operation of devices. At the end of the established service life, the equipment manufacturer shall take the object for disposal.

Apparently, in connection with such an essentially closed cycle of the use of equipment, the concept of Industry 4.0 is usually represented as a mathematical sign of infinity. This symbol symbolizes the continuity of the process of interaction between the equipment manufacturer and the product, and customers $[2,8]$.

\subsection{The features of Industry 4.0}

The founders of the concept of Industry 4.0 formulated several principles for its construction.

1. The principle of compatibility: the ability of machines, devices, sensors and people to interact and communicate with each other through the Internet of things.

2. The principle of transparency: the formation in the virtual world of a digital copy of real objects, as well as systems of functions that repeat everything that happens to a real physical object.

Thus, there is accumulation of quite complete information about all processes and the state of objects and equipment included in the "smart" production. At the same time, it is required to ensure the collection of all information from sensors and transducers in order to generate all information taking into account the features and values of each of the indicators.

3. The principle of technical support: the assistance of computer systems to personnel in decision-making in specific situations, based on the analysis and visualization of all available information. The full replacement of people with computers is possible in the future, especially in cases that threaten the health of people.

4. The principle of decentralization of managerial decisions: the delegation of some administrative functions to cyber-physical systems. The sense of implementation of the principle is that in all cases where the machine can work without human intervention, a transition to manless technology must be implemented. The person in this case acts as a controller, ready to make a decision in non-standard situations.

In the implementation of these principles in industry and transport, as well as in some other branches of the economy, there will inevitably be a change in the corresponding business processes and business models. For example, instead of focusing on lean production, companies can concentrate their attention on personalization of products, including transportation, as well as on the release of unique products (transportation) in single versions. It is important to note that at the same time the saving principle is maintained, since robot production provides higher product quality and minimization of failures and rejections [3].

\section{Results}

\subsection{Digital intelligent economics}


The new trends in technological and economic development of Industry 4.0 dictate the need for change at all levels of evolutionary development. At the first level - the conceptual one, the changes are connected with the adoption of managerial decisions. At the strategic level, a substantiation of priority directions of development, including the development of program documents, is required.

Currently, a new institutional environment is developed that contributes to innovative development and the emergence of new organizational structures [9]. In Europe, the most important changes in the innovation landscape include, in particular, the creation of European technology platforms. They include 9 platforms connected with information and communication technologies, including 5 platforms in the transport sector.

The technology of creation of the European technological platforms provides for such stages as:

- pooling the interests of stakeholders with a view to formulate a long-term development strategy;

- the development of the Strategic Plan and the Work Program for its implementation;

- implementation of the Strategic research plan using the mechanisms and scientific programs of the EU.

The developed technological platforms have so-called "mirror groups", which should provide a link between the activities of the European platform and the creation of products at the national and regional levels. A number of technological platforms in the EU are already in the third stage: "implementation of the strategic research plan." European single technological platforms unite efforts of private business, scientific and educational organizations, public and state bodies. This approach allows the creation of joint publicprivate projects (programs).

The fourth industrial-technological revolution led to drastic changes in the economy from micro- and meso levels to the level of the global economy. At the same time, the economy takes more and more new forms - from digital to the cloud one. At the same time, the economy and management of enterprises are faced with contradictions in the innovative development of engineering business. Specialists note the growing significance of the phenomenon of technicalization, digitalization in all spheres of economic life, including human activity. The information technologies form a virtual and augmented reality. At the same time, new stages, levels and problems of production development are observed:

- global challenges associated with the formation of the digital economy;

- digital transformation of industry and transport;

- problems of digitalization in the development of regional and branch economy;

- problems of economics and enterprise management in the digital economy;

- development of modelling tools and the rationale for the development of the digital economy.

\subsection{Digital railroads}

Speaking of a more specific topic, such as digital railways, the concept of "digital railroad", from the authors' point of view [4], should primarily be based on the use of safety-related devices. This is, as a rule, signaling and communication equipment (SCE). The issues of safety of transportation of goods and passengers on the railways have always been under increased attention [10-11]. It should be noted that the railway signaling system on the basis of "digitalization" already operates in a system of high-speed railways on a landfill with a total length of more than $80,000 \mathrm{~km}$. At the same time, the European Union of Railway Transport has created and well-proven digital railway signalling system based on a special system of standards. The transition from an analog signalling system to the digital one was first implemented on conventional railways in the UK. The specialists of this 
country believe that the transition to digital modernization of the railway will stimulate the overall stable growth of the country's economy [4].

The initiators of the transition to digital railways say that with this technology, it is possible to regulate technical, technological and economic indicators. In addition, the digital modernization of the railway increases the labour productivity, traffic safety, and customer-orientedness. It can be expected that a reduction in the negative impact on the environment will be achieved [12].

When launching the program of digitalization of railways in the UK, three goals were formulated. The first one is an increase in the number of trains on the existing infrastructure. The second one is the best alignment of traffic schedules. And the third one is more convenience for customers [4]. At the present stage of "digitalization" the authors do not take into account any kind of anomalies, in particular, the disconnection of digital components as a result of natural disasters.

The introduction of digital technologies into the country's transport system, according to experts, will promote more active industrial development and, ultimately, economic growth of the country. With limited financial resources in the industry, priority should be given to financing sectoral transport innovations, for example, the design of high-speed railroads using digital technologies. The most striking example here is the construction of high-speed railway lines, such as Moscow-Kazan, which is planned as part of the future mega-project of the Moscow-Beijing railway line [13]. The implementation of this scale of infrastructure projects is positioned as a priority in the economic policy of the Russian Federation.

In certain sectors of the economy, Russian companies show results at the world level and often have their competitive advantages. The domestic IT companies such as Mail.ru, Yandex, Kaspersky and others create products at the interface of information technology and the transport industry. The products of these companies are not inferior and even go ahead of their Western competitors. Even today's traditional activities (medical care, education, financial services) are transferred to the digital format.

In addition to the above-mentioned features and directions for the development of "digitalization" in the technical and technological aspects of transport systems, it is necessary to take into account the impact of digitalization on the behavior of passengers. According to some experts' estimates, the penetration rate of such devices as smartphones will reach $50 \%$ by 2019 . The fact that every second passenger or cargo owner will have gadgets, on the one hand, increases the mobility of citizens and on the other - raises the level of control over the movement of the cargo. In addition to widespread smartphones, new types of mobile devices appear, such as smart watches and bracelets, as well as promising virtual reality devices. The intelligent transport management systems receiving the right to use, having being until recently the part of the plots of fantasy novels, become a reality. All of the above will help increase the speed of transport and increase the level of comfort of living in various countries of the world, including, in Russia [13].

As a rule, the authors understand under the digital ecosystem a certain set of participants in economic activity (objects and subjects) and resources. Resources can be combined with a specific target orientation (education, construction, etc.) or industry affiliation. For example, an ecosystem of digital design and production in transport can include educational laboratories of universities, workshops, digital equipment, resources of companies and corporations. All elements of such ecosystems can effectively interact through cloud technologies.

One can say that fast-growing technological innovations create a mobile, virtual, supplemented contradictory world, when it is required in certain situations to weigh the pros and cons. New business processes require the development of technological and new economic thinking in all post- and neo-industrial sectors of the economy. At present, new economic-technological thinking becomes an intellectual part of the transforming economy. 
The digitalization as a result of the 4th industrial and technological revolution acquires global scales in the conditions of a changing economy.

\section{Conclusion}

Currently, the technological and economic aspects of the digitization of transport systems and railways, in particular, are the subject of discussions. The discussion is also taking place at the sites of the EAEC working group on the digital space.

The importance of the topic is determined by

1) determination and specification of directions and structural dynamics of national economic systems in the field of transport;

2) specification of the role of the information technology (IT) sector in structural dynamics in TSs;

3) determination of directions of further researches in the field of convergence of IT and management of electronic (digital) economic subsystem of states and territories.

The construction of a TS management system oriented to a wide exchange of information increases the efficiency of decision making and reduces the probability of error. When developing some schemes of cargo delivery in different climatic zones of the country using several modes of transport for synchronization of actions, it is possible to use a method similar to a "brainstorm", with involment of all participants of the transport process.

The researches conducted have shown that for increase of efficiency and innovative development of the TSs it is necessary to carry out their digitalization and transformation of the economy on the basis of modern tools and mechanisms.

Thus, the proper and effective application of the "large data" technology will play a positive role in optimizing the activities of logistics and transport enterprises in terms of management and decision making, as well as customer service and resource allocation.

\section{References}

1. K.E. Gafarova, E.I. Osadchiy, Economy and business: theory and practice 2, 52-55, (2016). (in Russian)

2. V.P. Kupriyanovskiy, D.E. Namiot, S.A. Sinyagov, International Journal of Open Information Technologies 4 (2), 19-25 (2016). (in Russian)

3. M. Hermann, T. Pentek, B. Otto, Design Principles for Industrie 4.0 Scenarios: A Literature Review Working Paper 01 (2015).

4. V.P. Kupriyanovskiy, D.E. Namiot, S.A. Sinyagov, A.P. Dobrynin, Modern Information Technology and IT-education 12 (1), 243-249 (2016). (in Russian)

5. N.S. Nesterova, S.M. Goncharuk, V.A. Anisimov, A.V. Anisimov, MATEC Web of Conferences 86, 05024 (2016).

6. K.L. Komarov, Issues of New Economy 1, 35-42 (2017). (in Russian)

7. K.L. Komarov, Politransport systems: Proceedings of the VIII International Scientific and Technical Conference "Scientific problems of transport projects implementation in Siberia and Far East" (Novosibirsk, 2015).

8. V.P. Kupriyanovskiy, A.P. Dobrynin, S.A. Sinyagov, D.E. Namiot, N.A. Utkin, International Journal of Open Information Technologies 5 (1), 34-49 (2017).

9. K. Chruzik, M. Sitarz, Mechanika 20 (4), 431-437 (2014).

10. K.L. Komarov, A.N. Ser`eznov, V.V. Murav`ev, L.N. Stepanova, E.U. Lebedev, S.I. Kabanov, M.V. Gerashchenko, Russian Journal of Nondestructive Testing 37 (3), 232-237 (2001). 
11. R. Brkić, Z. Adamović, Russian Journal of Nondestructive Testing 47 (6), 420-429 (2011).

12. M. Dedík, J. Gašparík, Z. Záhumenská, MATEC Web of Conferences 134, 00009 (2017).

13. T.N. Yudina, State and Municipal Management Scholar Notes. RANEPA 3, 139-143 (2017). 